\title{
Creatividad y estereotipia en el sadomasoquismo
}

Josefa Ruiz-Tagle

josefaruiz@gmail.com

"No es por medio del asesinato como se realiza el erotismo de Sade: es por medio de la literatura" Simone de Beauvoir

El BDSM ${ }^{1}$ y el posporno ${ }^{2}$ tienen muchas diferencias pero también más de algo en común. Y no me refiero a látigos o agujas, máscaras de cuero o puños insertos en el culo. Quienes participan de ambos movimientos, si se los puede llamar así, se creen dueños de una sexualidad radical, que a fuerza de creatividad podría ayudarlos a liberarse del yugo de identidades anquilosadas y destinos inapelables.

El documental de Lucía Egaña sobre la escena posporno en Barcelona, "Mi sexualidad es una creación artística"3, toma su nombre de la expresión utilizada por una de las protagonistas.

La lógica es la siguiente: si el sexo es uno de los elementos que determinan más poderosamente nuestra identidad, liberarnos del yugo de las convenciones, de los tabúes y los roles fijos y socialmente vigilados, éste podría, en efecto, permitir que nos inventáramos a nosotros mismos con mayor y renovada libertad. De manera semejante, muchos de los cultores del sadomaso no hablan de inclinaciones o prácticas, sino de "estilo de vida", es decir, algo más que un juego, algo que compromete la identidad y la globalidad de la existencia.

Influenciado por la militancia SM-lésbica de los años 70, el propio Michel Foucault, maestro de la sospecha, adhiere a esta convicción... 
La sexualidad forma es algo que nosotros mismos creamos -es nuestra propia creación, tanto más cuanto no es el descubrimiento de un aspecto secreto de nuestro deseo-. (...) El sexo no es una fatalidad, es una posibilidad de acceder a una vida creadora (1999, 417).

Y más tarde agrega:

No pienso que ese movimiento de prácticas sexuales haya tenido nada que ver con la puesta al día o el descubrimiento de tendencias sadomasoquistas profundamente soterradas en nuestro inconsciente. Pienso que el S/M es mucho más que eso, es la creación de posibilidades de placer que no se habían imaginado con anterioridad $(1999,419)$.

Sin embargo, frente a este exceso de entusiasmo, la pregunta que cae de cajón es: ¿Es posible la libertad sexual? Es decir, ¿es posible un sexo que no obedezca a la necesidad? ¿Es posible un sexo en el cual, más allá de las buenas intenciones, estemos liberados de impulsos primitivos y del yugo de nuestras novelas familiares?

En su libro titulado ¿Hay que quemar a Sade?, Simone de Beauvoir señala un par de puntos que resultan al respecto iluminadores: "Si los héroes de Sade multiplican indefinidamente las masacres es porque nada los sacia." (2002, 59). Y suma: "Sade no nos ofrece la obra de un hombre liberado: nos hace participar en su esfuerzo de liberación" (2002, 74).

Si bien la herencia de Sade en el moderno sadomasoquismo es relativa y ha sido cuestionada, me parece que en este punto, el de la búsqueda de la libertad, tanto los héroes de las novelas del marqués como los cultores del BDSM persiguen un espejismo semejante.

Después de una década de estudio etnográfico en diversos antros sadomasoquistas en Internet, he llegado a convencerme de que la inmensa mayoría de quienes circulan por allí nunca ha empuñado un látigo.

Sus actividades se limitan a interminables conversaciones por chat, exhibiciones por cámara web y escritura de blogs. También -y aquí es donde desarrollan sus talentos más exquisitos- al intercambio de correos electrónicos con personas que viven a miles de kilómetros de distancia, un intercambio que puede durar décadas, en el que 
planifican las barbaridades que harán cuando se encuentren, mientras dilatan este encuentro lo más posible probablemente a sabiendas de que resultará un fracaso.

Vuelvo a citar a De Beauvoir: “El momento del complot es para el libertino un momento privilegiado porque puede ignorar entonces el desmentido que le opondrá la realidad." (2002, 62). Lo que nos quiere decir la autora, así lo explica en su libro, es que, en el contexto del libertinaje, la crueldad es una práctica difícil de ejercer sino es dentro de límites muy modestos. El exceso de sufrimiento provoca asco y el asco es contrario al placer. Además, como veremos más adelante, ningún masoquista desea exponerse a los excesos del sádico.

Concluye ella entonces que "sólo hay una manera de satisfacerse con los fantasmas que crea el libertinaje: Contar con su irrealidad misma." $(2002,62)$. Conclusión, a mi parecer, de la mayor relevancia para la reflexión acerca de las prácticas sexuales al interior de la web 2.0. Los diálogos interminables por Internet se prestan para vivir imaginariamente todo tipo de perversiones y fechorías. Permiten a los dueños de imaginaciones afiebradas evitar la frustración de confrontarse a imágenes de sí mismos vulgares e inofensivas.

$Y$ eso es lo que sucede cuando estos individuos se encuentran y se ven obligados a reconocerse en la mirada del otro. Los sujetos reales, con su pesada carga de moralidad, superan en densidad a los fantasmas dominantes y sumisos que han construido. Los resortes del yo y el superyó vuelven a operar sujetándolos dentro de las estrechas fronteras de sus costumbres. Por más que vivan momentos intensos, acaban tomando té y viendo la tele, echando así por tierra lo largamente tejido en el infierno de sus fantasías.

Más grave aún es lo que ocurre cuando alguno no reconoce las señales del carácter irreal de sus fantasías. A propósito de esto, la cronista argentina María Moreno, nos relata el caso un ama de casa de Baltimore que buscó a través de Internet a un hombre que la torturara hasta matarla. Cito:

Quizás Sharon al teclear la frase "busco a un hombre que me torture sexualmente hasta matarme", como suele suceder para expresar la lujuria, estaba utilizando una metáfora. Sólo que Robert no tenía la finura de la Venus de las pieles ni la gracia retórica del divino 
marqués, básicamente experto en orgías de palabras evocadoras de una organización obsesiva y hasta tediosa. Robert tomó todo al pie de la letra. (...) Entonces cabe una hipótesis de humor negro: lo que verdaderamente mató a Sharon fue la irrupción de un grosero partidario del realismo en medio de una parodia posmoderna $(2002,109)$.

Sin embargo, sólo en su exceso las fantasías sadomasoquistas están condenadas a frustrarse. Cuando los jugadores son realistas -cuando no aspiran a la degradación máxima, a la esclavitud completa, a la tortura extrema y la renuncia absoluta a la voluntad (aspiraciones relativamente comunes dentro del BDSM, al menos en su formulación verbal)- cuando lo que buscan es a explorar, dentro de ciertos límites razonables, el intercambio de poder, tienen la posibilidad de llevar a la práctica sus planes.

Lo que no significa que la planificación y la palabra no cumplan para ellos un rol fundamental. Gilles Deleuze, en su ensayo Lo frío y lo cruel, a propósito de la vida y la obra de quien le diera el nombre al masoquismo, Leopold von Sacher Masoch, señala lo siguiente:

Es preciso que los amores tengan por disparador cartas firmadas con pseudónimo y avisos clasificados; que estén regulados por contratos que los formalicen, que los verbalicen; y las cosas sean dichas, prometidas, anunciadas y cuidadosamente descritas antes de consumarse $(2001,22)$.

Entonces, a los herederos de Masoch no les lleva años encontrarse ni sus encuentros tienen como resultado necesariamente la frustración, pero sin duda sus formas de relación y de cortejo son un precedente de lo que hoy ocurre en la web.

Sadismo y masoquismo no son dos caras de una misma moneda. Existen herederos de Sade y herederos de Masoch y ellos son radicalmente distintos. Las fantasías sádicas, como hemos visto, están atrapadas en su destino irrealizable, o forman parte de realidades horrorosas como la Venda Sexy o Auschwitz. Su deseo es la degradación moral del otro, como tan bien ilustró Pasolini en su terrible Saló.

La imaginación de Sacher Masoch transita por caminos diferentes. Los iniciados en las artes del sadomaso pertenecen a este universo. Para echar a andar la máquina masoquista, la complicidad 
entre víctima y victimario es necesaria. El dolor y la humillación sólo interesan en tanto gatillantes del goce.

Todo esto ha sido enunciado por Deleuze. Cito:

Jamás un verdadero sádico soportará a una víctima masoquista. (...) Pero tampoco un masoquista soportará a un verdugo verdaderamente sádico. (...) Si la mujer-verdugo no puede ser sádica en el masoquismo, es precisamente porque está en el masoquismo, porque forma parte de la situación masoquista, en su carácter de elemento realizado del fantasma masoquista: ella pertenece al masoquismo. (...) No es ni verdadera sádica ni falsa sádico, ni falsa sádica, sino algo muy diferente (...) que encarna el "hacer sufrir" desde una perspectiva exclusivamente masoquista $(2001,35)$.

Una de las características fundamentales que tiene esta "situación masoquista" enunciada por Deleuze es el pacto. Pacto que se va renovando en cada gesto, en cada cita, y que depende del deseo de los involucrados más que de cualquier convención. No hay, en el masoquista, posibilidad de goce solitario.

La mayor parte de las veces este pacto es explícito. En él se definen principalmente los límites. A veces asumen incluso la forma de un contrato escrito. Muchos de ellos circulan por Internet. Se los recomiendo: son delirantes y denotan evidente gozo en su ideación.

Por escrito o no, la negociación sobre los límites suele ser tan detallada que desarticula toda posibilidad de violencia real, y en este sentido nos obligan a preguntarnos si el sadomasoquismo, tal como es vivido en las comunidades BDSM hoy, no es acaso un esfuerzo por encauzar, contener, y finalmente, negar, la violencia propia de las relaciones signadas por el sexo.

De todo lo anterior se desprende una de las ideas clave que muchos sadomasoquistas tienen sobre sus prácticas: El SM no reproduce las estructuras de poder presentes en la sociedad, sino que las desnaturaliza y/o las parodia a través de la escenificación y del juego.

Un ejemplo de esto, nos da Pat Califia, en su manifiesto de 1979 "Un lado oculto de la sexualidad lésbica". Cito: "En un contexto sadomasoquista, los uniformes, roles y diálogos se convierten en una parodia de la autoridad, un desafío para esta, un reconocimiento de 
su naturaleza sexual secreta." $(2008,150)$.

Sin embargo, si bien la parodia exige una distancia y un juicio crítico, mucho más ambicioso es Foucault cuando otorga al sadomasoquismo la capacidad de "creación de nuevas posibilidades que no se habían imaginado con anterioridad", ambición que como vimos comparte con los cultores del posporno.

A propósito de la parodia, Simone de Beauvoir hace una ruda crítica a Sade: “Es normal, y a la vez chocante, que el género favorito de Sade sea la parodia. No se trata de instituir un universo nuevo, sino que se limita a hacer burla." $(2002,68)$.

En eso radicaría, para la autora, la mediocridad estética de Sade: en que formalmente no inventó nada, sino que se limitó a tomar prestadas formas estéticas y retóricas de aquel mundo que despreciaba.

La pregunta que surge entonces es: ¿qué tan efectiva ha sido la subcultura sadomaso en su intento de crear formas y posibilidades que no se habían imaginado con anterioridad?

Si bien, tal como Foucault señala, el SM, en tanto comunidad, surgió en San Francisco en los años 70, el masoquismo fue descrito por Sacher Masoch en su novela testimonial La venus de la pieles en 1870; bautizado y sometido a la categoría patología psiquiátrica por Krafft-Ebing en 1890 e interpretado por Freud en 1924. Sin contar las múltiples expresiones anteriores, tan ricas, por ejemplo, en la imaginería católica. Ya desde el siglo IX a.C. es posible encontrar referencias en la historia del arte y la literatura a actividades eróticas masoquistas consensuadas.

Nada de esto contradice la creatividad del moderno sadomasoquismo. No existe empresa creativa que no se inserte en tradiciones culturales. Otra cosa, sin embargo, es repetir sin más que pequeñas variaciones un modelo y un discurso ya trillados. $\mathrm{Y}$ lamentablemente eso es lo que ocurre.

Los discursos son tan similares entre un sadomasoquista y otro que es evidente que "la comunidad", como la llaman, tiene un gran paralelo con la Iglesia, con sus múltiples parroquias y sus disquisiciones bizantinas; con sus sacerdotes y sus monjas; con sus credos, leyes y encíclicas papales. Atreverse a criticar algún dogma puede acarrear la excomunión.

No exagero. La creatividad se bate en retirada. Es cierto que el 
masoquismo vive de la repetición compulsiva de rituales. Es verdad, como hemos visto, que requiere de un guiones para desatar la acción, y es cierto también que éstos no serán nunca del todo originales. Pero es posible al menos esperar que no sean enteramente escritos por otros y adoptados de manera acrítica, sin ninguna alusión al contexto.

No sólo se renuncia así a la creatividad, sino, además, los involucrados se tornan marionetas de un teatro que sucede fuera del tiempo, en sitio alguno. Lo mismo en Puerto Montt, en Texas o en Seúl. Sin densidad biográfica ni social, nadie es afectado. Quizás por eso María Moreno afirmó que más allá del escándalo que provoca el SM en los tontos, mucho más violento y peligroso es el amor no correspondido.

Otro aspecto del BDSM en el que la creatividad se ha estancado es en la estética visual. Y en esto sí que la herencia sadiana es evidente.

El claroscuro de castillos misteriosos y mazmorras, las cadenas, antorchas, jaulas y potros de tortura, todo ello pertenece al mundo de Sade. Sin embargo, el siglo $X X$ con su trituradora industrial convirtió la densidad de este imaginario gótico en pura parafernalia kitsch.

Los espléndidos castillos devinieron escenografías de cartón piedra; las monjas muchachas disfrazadas con minifaldas de charol; y los aristócratas perversos tipos enguantados en cuero. Todo fabricado por menores de edad, el único sadismo real en la cadena; comprado en sex shops por Internet e importado desde China.

Los látigos se rompen ante la menor violencia, las fustas traen estampados corazones, las máscaras de látex amenazan con alergias y los corsés estallan al intentar ceñir los cuerpos abundantes de señoras que sólo mueven los músculos que usan para chatear.

Resulta difícil tomarse en serio todo esto. No porque sea una parodia. La mayoría de las veces tampoco es camp. No hay ironía alguna, ni burla, ni voluntad de resignificación. Tan solo productos elaborados en serie, desarrollados a partir de estudios de mercado para públicos extraordinariamente estereotipados. En suma, puro kitsch.

Ahora bien, no todo es color de hormiga. No todos están atrapados en pequeños nichos de mercado. No son pocos los que han hecho, a partir del sadomasoquismo, arte, literatura o performance crítica 
y creativa. De todo hay. Desde las obras notables de Bob Flanagan ${ }^{4}$ hasta la basura corintelladesca de Cincuenta sombras de Grey ${ }^{5}$.

Démosle, también, algún crédito a Foucault. La sexualidad sadomaso sí ha hecho aportes a la exploración del cuerpo y las posibilidades del erotismo, y es de esperar que éstos se estén viralizando a través de los veloces y omnipresentes canales de la pornografía.

Las jerarquías de poder entre los sexos, comúnmente son invertidas en el juego SM y, de esta manera, se las ha desnaturalizado. Hombres asumen de buena gana roles sumisos antes mujeres fálicas. Las posiciones dentro del tablero en donde se desarrolla el juego estratégico no son social ni culturalmente determinadas, tampoco suponen privilegios ni degradan.

En cuanto a la exploración de partes del cuerpo que habían permanecido inexploradas, la erotización del ano es lo más evidente. Y si bien la sodomía se ha practicado desde que el tiempo es tiempo, ahora las mujeres le entran de lleno al asunto, ya no sólo siendo penetradas, si no también penetrando.

No es raro que las heroínas de Sade tengan vaginas obstruidas o clítoris de varios centímetros de largo con los que penetran a muchachas y muchachos. En el BDSM, el uso de prótesis ha liberado a las personas de las limitaciones de la anatomía, quitándole al pene su exclusividad. ¡Cómo no citar aquí la maravillosa sentencia de Beatriz Preciado: "el pene es un dildo de carne" (2011)!

Por el lado de las sensaciones, "lo agradable" pierde el trono, o más bien pasa a compartirlo con la frustración, el tormento, la humillación, el suspenso y el miedo. No es que estas cuestiones estén ausentes del erotismo en su generalidad, la novedad es que ahora se las asume como algo deseable y se las busca de manera abierta.

Para alcanzar estas sensaciones se echa mano de una serie de nuevos elementos. Por ejemplo, la hediondez, la grosería, la decadencia y la fealdad, elementos mostrados ya en todo su potencial voluptuoso en el monólogo final de Molly Bloom en el Ulises de Joyce.

Existe también una tendencia pansexual en el sadomasoquismo expresada en la literatura de Sade y ampliamente difundida entre los modernos cultores. No es raro observar en los portales de BDSM que las búsquedas no se dirigen a un sexo en particular si no a quienes comparten ciertos fetiches, gustan de ciertas prácticas o asumen un 
determinado rol, se definan estos como mujeres, hombres, travestis, queer, transexuales.

Más allá de cualquier valoración, el abandono del modelo heteronormativo; la apertura de la pareja hacia formas colectivas, promiscuas o poliamorosas; la dignificación del trabajo sexual; la desgenitalización del sexo y la valoración del juego son formas de abrir el naipe de la sexualidad de las que el SM ha participado.

Ahora, y para finalizar, quiero reflexionar sobre un último punto: ¿debe el SM salir del clóset? ¿Tiene algún sentido hacer de su pasión una bandera?

Según lo expresado en los testimonios recogidos por Lucía Egaña en el citado documental "Mi sexualidad es una creación artística" algunas de las intenciones fundamentales del posporno es educar a la comunidad en las posibilidades de gozo y libertad que ofrece el sexo, y hacer de prácticas hasta ahora abyectas, cuestiones aceptables para la sociedad.

Pero, ¿es deseable la transparencia? ¿Es deseable un mundo en el que los deseos sexuales dejen de ser opacos y se vuelvan moneda de cambio corriente, descritos en el perfil de Facebook y el currículum vitae? ¿Es posible un sexo sin culpa y sin pudor?

En lo concerniente al SM, al menos, esto parece un contrasentido, ya que, como expresara Sade, "no es el objeto del libertinaje lo que nos excita, es la idea del mal." (2002, 57). Es decir, pueden normalizarse todos los demás fetiches, menos el afán de profanar, de transgredir.

Protegidos por contraseñas, por biografías fantasiosas, por IPs fantasmas, pseudónimos y fotos robadas, los modernos sadomasoquistas se ocultan de la mirada pública, no porque teman al castigo, al menos no únicamente, sino porque gustan de la oscuridad y del secreto. Nada hay menos erótico que una playa nudista.

Los herederos de Masoch debieran exigir protección constitucional de la privacidad. También, de la igualdad ante la ley y del respeto a la diversidad de estilos de vida, prácticas, estéticas y relaciones consentidas entre adultos informados.

Es probable que lo hagan, ya a que a diferencia de los héroes sadianos, suelen ser personas liberales e incluso tediosamente razonables. Su escenificación de la violencia, recordemos, no es más que un intento de desarticular el potencial destructivo del deseo y el sexo; y los crímenes a los que aspiran no son más que crímenes 
imaginarios.

Para el resto, siempre tendrán, como todos, la literatura, el arte y el duro corazón 6 de la pornografía, en donde contemplar, protegida y gozosamente, las peores aberraciones que la imaginación humana sea capaz de elaborar

\section{Notas}

1. BDSM es acrónimo de bondage (ataduras eróticas), disciplina (azotes), dominación y sumisión, y sadomasoquismo. BDSM define tanto a aquellas disciplinas como a la subcultura de quienes las practican, ya sea como estilo de vida o en forma circunstancial. Aun cuando algunos de los cultores del BDSM podrían no estar de acuerdo, en el siguiente texto utilizaré indistintamente las expresiones "BDSM", "SM", "sadomaso" y "sadomasoquismo" por considerar que las distintas disciplinas agrupadas en el BDSM son formas de sadomasoquismo.

2. Por posporno o pospornografía me refiero aquí a una serie expresiones contraculturales que a través de la reapropiación y subversión de los códigos de la pornografía industrial realizan una revisión crítica de su carácter sexista y heteronormativo.

3. El documental "Mi sexualidad es una creación artística" fue realizado en Barcelona durante el año 2010 por Lucía Egaña, artista visual chilena. Es posible ver un tráiler de esta película en el siguiente sitio web: http://goo.gl/WqTyt.

4. Bob Flanagan (1952-1996) fue un dibujante, instalador, performancista y escritor neoyorquino relacionado con la subcultura del BDSM.

5. Cincuenta sombras de Grey es la primera entrega de una trilogía de novelas eróticas con contenidos BDSM de la autora británica E.L. James. De acuerdo a Wikipedia la serie ha vendido 31 millones de copias en 37 países y su edición de bolsillo se ha convertido en la vendida con más rapidez de todos los tiempos, superando así a la saga Harry Potter.

6. Se alude aquí al hardcore, i.e. porno duro.

\section{Bibliografía}

Califia, Pat. “Un lado oculto de la sexualidad lésbica.” 1979. En Weinberg, Thomas [ed.], BDSM. Estudios sobre la dominación y la sumisión. Barcelona: Ediciones Bellaterra, 2008.

de Beauvoir, Simone. ¿Hay que quemar a Sade? 1955. Madrid: A. Machado Libros, 2002.

Deleuze, Gilles. Lo frío y lo cruel. 1968. Buenos Aires: Amorrortu, 2001.

Foucault, Michel. “Una entrevista: Sexo, poder y política de la identidad”. 1982. Estética, ética y hermenéutica, Obras esenciales Volumen III. Barcelona: Editorial Paidós, 1999.

Moreno, María. El fin del sexo y otras mentiras. Buenos Aires: Editorial Sudamericana, 2002.

Preciado, Beatriz. Manifiesto Contrasexual, 1998, Barcelona: Anagrama, 2011. 